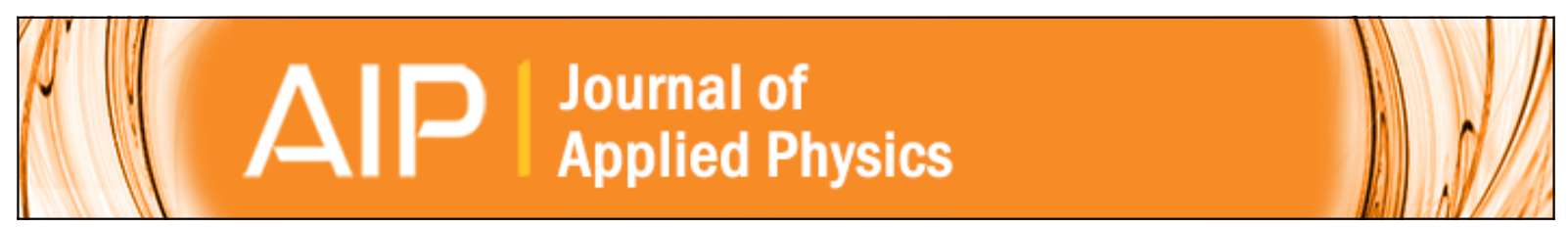

Prolonged and rapid thermal annealing of boron implanted silicon

C. R. Peter, J. P. de Souza, and C. M. Hasenack

Citation: Journal of Applied Physics 64, 2696 (1988); doi: 10.1063/1.341610

View online: http://dx.doi.org/10.1063/1.341610

View Table of Contents: http://scitation.aip.org/content/aip/journal/jap/64/5?ver=pdfcov

Published by the AIP Publishing

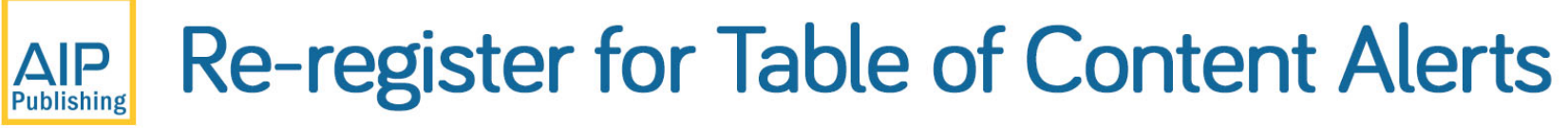

Create a profile. 


\section{Prolonged and rapid thermal annealing of boron implanted silicon}

C. P. Peter

Sid Microeletrônica S.A., 32210 Contagem, M.G., Brasil

J.P. de Souza ${ }^{a}$ and C. M. Hasenack ${ }^{\text {? }}$

Instituto de Fisica, UFRGS 90049 Porto Alegre, R.S., Brasil

(Received 22 January 1988; accepted for publication 1 May 1988)

We studied the annealing of silicon substrates implanted with a medium dose of boron ions $\left(3 \times 10^{14} \mathrm{~cm}^{-2}, 150 \mathrm{keV}\right)$ employing conventional furnace annealing ( $\left.F A\right)$ and rapid thermal annealing (RTA) processes performed in a nitrogen atmosphere. The annealing efficiency was monitored by visual inspection of the implanted surface with an optical microscope after steam oxidation and Secco etching. The FA is more efficient when performed at a high temperature, but even so, it is not capable of suppressing completely the implantation damage. On the other hand, the RTA was observed to be more efficient than any FA cycle. We discuss this fact taking into account the influence of the very high heating rates $\left(-250^{\circ} \mathrm{C} / \mathrm{s}\right)$ the samples underwent during the RTA cycle on the annealing behavior of implantation damage.

\section{INTRODUCTION}

The ion implantation into crystalline silicon leaves this material highly damaged so that it becomes improper for electronic applications unless an adequate annealing process restores to a high degree the original crystallinity. Depending on the energy, mass, and dose of the bombarding ion, the implanted surface can be rendered amorphous. In the last years, a larger number of publications referred to the annealing of such amorphized layers by means of rapid thermal annealing at temperatures ranging from $900-1200^{\circ} \mathrm{C}$ and times of a few to hundreds of seconds. ${ }^{1}$ In that way, the amorphized layer can be solid phase epitaxially recrystallized, and the resuit is a very low residual defect density and a high electrical activation yield of the implanted dopants.

The use of ion implantation conditions that do not render the surface amorphous is a common case in integrated circuit technologies. Typical examples are the doping processes of bipolar transistor bases, threshold adjustment of MOS transistors, $p$-and $n$-well doping of CMOS, and feld doping. ${ }^{2}$ These cases refer to implantation of low doses of heavy mass ions ( $\left.<10^{14} \mathrm{~cm}^{-2}\right)$ or low to medium doses of light mass ions $\left(<10^{15} \mathrm{~cm}^{-2}\right)$. The annealing of the implantation damage in such cases has already been studied employing prolonged thermal cycles in inert ${ }^{3-6}$ and in $\mathrm{HCl}$ added to dry oxygen atmospheres. ${ }^{7,8}$ For the case of inert atmosphere anneals, it was demonstrated that an efficient suppression of implantation defects is only achieved after high-temperature treatments $\left(T>1000^{\circ} \mathrm{C}\right)$. Despite the above-mentioned applications, very few studies of the annealing of nonamorphized implanted silicon layers employing RTA have been reported in the literature.

In this work, we studied the annealing of medium dose boron implantation by FA and RTA in nitrogen atmosphere. It is well known that oxidation of such as-implanted or partially annealed samples leads to the generation of a high density of extended defects. These are basically disloca-

\footnotetext{
a) Present address: Thomas I. Watson Research Center, IBM, Yorktown Heights 10598

b) Present address: Interuniversicy Microelectronics Center (IMEC), Kapeldreef 75, B-3030 Leuven, Belgim.
}

tion loops (DL) and oxidation stacking faults (OSF), the origin of which are the nuclei provided by the crystalline defects induced by the ion implantation. ${ }^{9}$ We used this fact to monitor the annealing efficiency by optical microscopy after steam oxidation and Secco etching ${ }^{10}$ of impianted silicon surfaces. We discuss the annealing behavior of rapid and prolonged thermal treatments based on a model that takes into account the temperature evolution of the samples during the annealing cycles.

\section{H. EXPERIMENTAL METHODS}

In this work, we used $p$-type Czochralski silicon wafers of (100) orientation and of $4 \Omega \mathrm{cm}$ resistivity, with an $n$-type epitaxial overlayer. The resistivity and thickness of this epilayer was $3.5 \Omega \mathrm{cm}$ and $15 \mu \mathrm{m}$, respectively. The epilayer was $\mathrm{B}^{+}$implanted to a dose of $3 \times 10^{14} \mathrm{~cm}^{-2}$ at an acceleration energy of $150 \mathrm{keV}$. One set of samples was submitted to FA at temperatures ranging from 480 to $1200{ }^{\circ} \mathrm{C}$ and for times from 1 to $10 \mathrm{~h}$. A second set of samples was submitted to RTA employing incoherent radiation from tungsten-halogen lamps. The annealing temperature was monitored with the aid of a thermocouple that was attached to a similar sample by ceramic cement mixed with silicon powder. The annealing time was considered as being the time interval during which the samples were kept at the nominal temperature. We experimented with RTA thermal cycles at 1000 , 1100 , and $1200^{\circ} \mathrm{C}$ during $l$ and $25 \mathrm{~s}$, in nitrogen atmosphere.

All thermal treated samples, together with one unannealed sample (control sample) were oxidized in a steam atmosphere at $1150^{\circ} \mathrm{C}$ for $30 \mathrm{~min}$ in order to grow extended defects from the nuclei provided by the residual defects. The grown oxide was then chemically removed and subsequently, all samples were submitted to a Secco etch for $30 \mathrm{~s}$. Lattice defect figures delineated by Secco etching were observed using an optical microscope in order to determine their structures, densities, and sizes.

\section{EXPERMENTAL RESULTS}

In Table 1 , the densities of defects and OSF lengths observed on the samples are displayed. By OSFBI we refer to a 
TAELE I. Defect structures observed on the samples submitted to FA.

\begin{tabular}{cccccc}
\hline $\begin{array}{c}\text { Amneal } \\
\text { temperature } \\
\left({ }^{\circ} \mathrm{C}\right)\end{array}$ & $\begin{array}{c}\text { Anneal } \\
\text { time } \\
(\mathrm{h})\end{array}$ & $\begin{array}{c}\mathrm{OSF} \\
\text { density } \\
\left(10^{4} \mathrm{~cm}^{-2}\right)\end{array}$ & $\begin{array}{c}\text { DL } \\
\text { density } \\
\left(10^{5} \mathrm{~cm}^{-2}\right)\end{array}$ & $\begin{array}{c}\text { OSFBI } \\
\text { density } \\
\left(10^{5} \mathrm{~cm}^{-2}\right)\end{array}$ & $\begin{array}{c}\text { OSF } \\
\text { length } \\
(\mu \mathrm{m})\end{array}$ \\
\hline $\begin{array}{c}\text { Control } \\
480\end{array}$ & $\begin{array}{c}\text { Sample } \\
480\end{array}$ & 0.5 & 100 & 0 & $<20$ \\
480 & 5 & 40 & 50 & 0 & $<15$ \\
800 & 10 & 30 & 50 & 0 & $<18$ \\
800 & 1 & 2 & 50 & 0 & $<22$ \\
800 & 10 & 2 & 80 & 0 & $<15$ \\
1100 & 1 & 2 & 80 & 0 & $<15$ \\
1100 & 3 & 1 & 30 & 0 & $<15$ \\
1100 & 5 & 0.1 & 2 & 10 & $3-12$ \\
1200 & 1 & 0 & 0.02 & 10 & $3-12$ \\
1200 & 3 & 0.04 & $<0.01$ & 2 & $3-12$ \\
1200 & 5 & 0.08 & 0 & 0 & 25 \\
& 5 & 1 & 0.05 & 32 \\
\hline
\end{tabular}

kind of defect structure of eiliptical shape, having a maximum length of about $5 \mu \mathrm{m}$ and being aligned to the $\langle 110\rangle$ directions. We identified this kind of defect structure with the one referred to by Rozgonyi and Seidel ${ }^{9}$ as being small bulk stacking faults generated by the oxidation of boron im. planted silicon layer and labeled as OSFBI.

\section{A. Prolonged firmace annealing}

Figure 1(a) shows the etch patterns of an as-implanted sample which was steam oxidized (control sample) and the
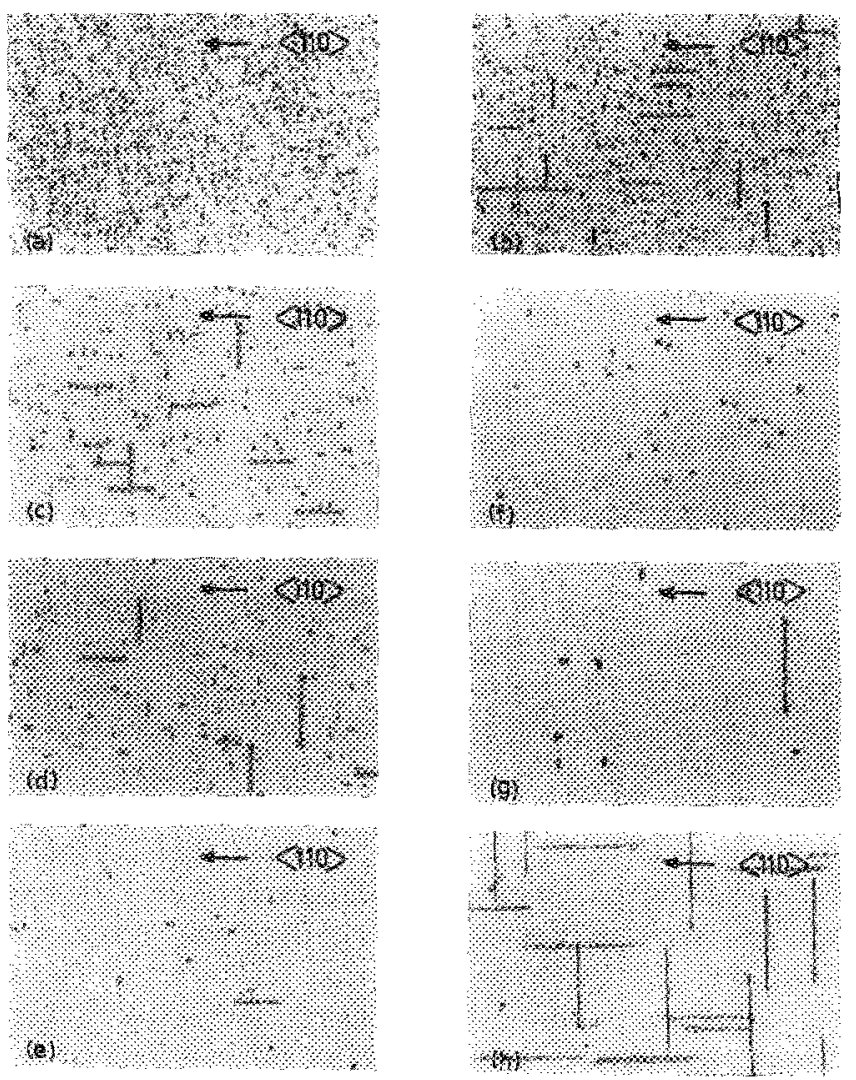

FIG. 1. Hhotomicrograpis showing the defect etch patterns of the samples submitted to FA. (a) Control sample, (b) sample annealed at $480^{\circ} \mathrm{C}$ for 1 $\mathrm{h}$, (c) sample annealed at $1100^{\circ} \mathrm{C}$ for $1 \mathrm{~h}$, (d) sample annealed at $1100^{\circ} \mathrm{C}$ for $3 \mathrm{~h}$, (e) sample annealed at $1100^{\circ} \mathrm{C}$ for $5 \mathrm{~h},(\mathrm{f}$ ) sample anneales at $1200^{\circ} \mathrm{C}$ for $1 \mathrm{~h},(\mathrm{~g})$ sample annealed at $1200^{\circ} \mathrm{C}$ for $3 \mathrm{~h}$, and (h) sample annealed at $1200^{\circ} \mathrm{C}$ for $5 \mathrm{~h}$, Secco etch $30 \mathrm{~s}$, magnification of $800 \times$.
Figs. $1(b)-1(\mathrm{~h})$ show the etch patterns of the samples submitted to different FA cycles. A large density of dislocation loop (DL) etch pits $\left(\sim 10^{7} \mathrm{~cm}^{-2}\right)$ and a OSF density of $10^{3} \mathrm{~cm}^{-2}$ can be observed.

The annealing performed at $480^{\circ} \mathrm{C}$ (independent of the duration, 1 to $10 \mathrm{~h}$ ) just reduced the OL-etch pit density by half but increased the OSF density by about two orders of magnitude [see Fig. 1(b)].

The samples annealed at $800^{\circ} \mathrm{C}$ for 1,5 , and $10 \mathrm{~h}$ display etch patterns similar to the samples annealed at $480^{\circ} \mathrm{C}$ but present a slight ty reduced OSF density. The annealing cycles performed at $1100^{\circ} \mathrm{C}$ for 1 and $3 \mathrm{~h}$ resulted in a reduction of the DL-etch pit density by about two orders of magnitude when compared to the control sample. On the other hand, the OSF density is still comparable to the one of the control sample [see Fig. 1(c) and 1(d)]. The annealing performed during $5 \mathrm{~h}$ provided further reduction of the DL-etch pits and of the OSF densities, respectively, by about four and one order of magnitude with respect to the control sample [see Fig. $1(e)]$. On all the annealed samples at $1100^{\circ} \mathrm{C}$ we observed OSFBI with densities in the range of $10^{6}$ ( 1 and $3 \mathrm{~h}$ ), and $10^{5} \mathrm{~cm}^{-2}(5 \mathrm{~h})$.

The oxidation of samples annealed at $1200^{\circ} \mathrm{C}$ for $1 \mathrm{~h}$ did not result in OSF generation, but did generate defects like DL and OSFBI with densities of $5 \times 10^{3} \mathrm{~cm}^{-2}$ and of $5 \times 10^{5} \mathrm{~cm}^{-2}$, respectively [see Fig. 1(f)]. However, for the sample annealed for $3 \mathrm{~h}$ [ [see Fig. $1(\mathrm{~g})]$, we observed again the generation of OSF, with a density of $4 \times 10^{2} \mathrm{~cm}^{-2}$ and of $25-\mu \mathrm{m}$ length. For this sample, the DL-etch pit and OFSBI densities are lower than in the sample annealed for $1 \mathrm{~h}$, being respectively, of $10^{3}$ and $2 \times 10^{5} \mathrm{~cm}^{-2}$. The sample annealed for $5 \mathrm{~h}$ [ [see Fig. i (h)] only present OSF of $32-\mu \mathrm{m}$ length, which pattern is somewhat different from that observed on all other samples. For this case, the etch pits commonly presented at the OSF extremities are absent and some line segments making $45^{\circ}$ with the $\langle 110\rangle$ directions appear associated with the OSF.

\section{B. Rapid thermal arneasing}

In Table II we quote the extended defect densities and OSF lengths extracted from the analysis of the samples sub. mitted to RTA and steam oxidation. The annealing performed at $1000^{\circ} \mathrm{C}$ for $1 \mathrm{~s}$ did not reduce the $\mathrm{OSF}$ generation, remaining the OSF density comparable to that of the control sample [see Fig. 2(a)]. However, the DL-etch pit density

TABLE I. Defect structures observed on the samples submitted to RTA.

\begin{tabular}{crcccc}
\hline $\begin{array}{c}\text { Anneal } \\
\text { temperature } \\
\left({ }^{\circ} \mathrm{C}\right)\end{array}$ & $\begin{array}{c}\text { Anneal } \\
\text { time } \\
(\mathrm{s})\end{array}$ & $\begin{array}{c}\text { OSF } \\
\text { density } \\
\left(10^{3} \mathrm{~cm}^{-2}\right)\end{array}$ & $\begin{array}{c}\mathrm{DL} \\
\text { density } \\
\left(10^{4} \mathrm{~cm}^{-2}\right)\end{array}$ & $\begin{array}{c}\text { OSFBI } \\
\text { density } \\
\left(10^{5} \mathrm{~cm}^{-2}\right)\end{array}$ & $\begin{array}{r}\text { OSF } \\
\text { length } \\
(\mu \mathrm{m})\end{array}$ \\
\hline 1000 & 1 & 5 & 8 & 1 & 25 \\
1000 & 25 & 0 & 0.4 & 1 & 0 \\
1100 & 1 & 0 & $6^{2}$ & 0 & $<35$ \\
1100 & 25 & 0 & $<0.1$ & 3 & 0 \\
1200 & 1 & 0 & $<0.1$ & 5 & 0 \\
1200 & 25 & 0 & $<0.1$ & 3 & 0 \\
\hline
\end{tabular}

"Unidentified structure. 

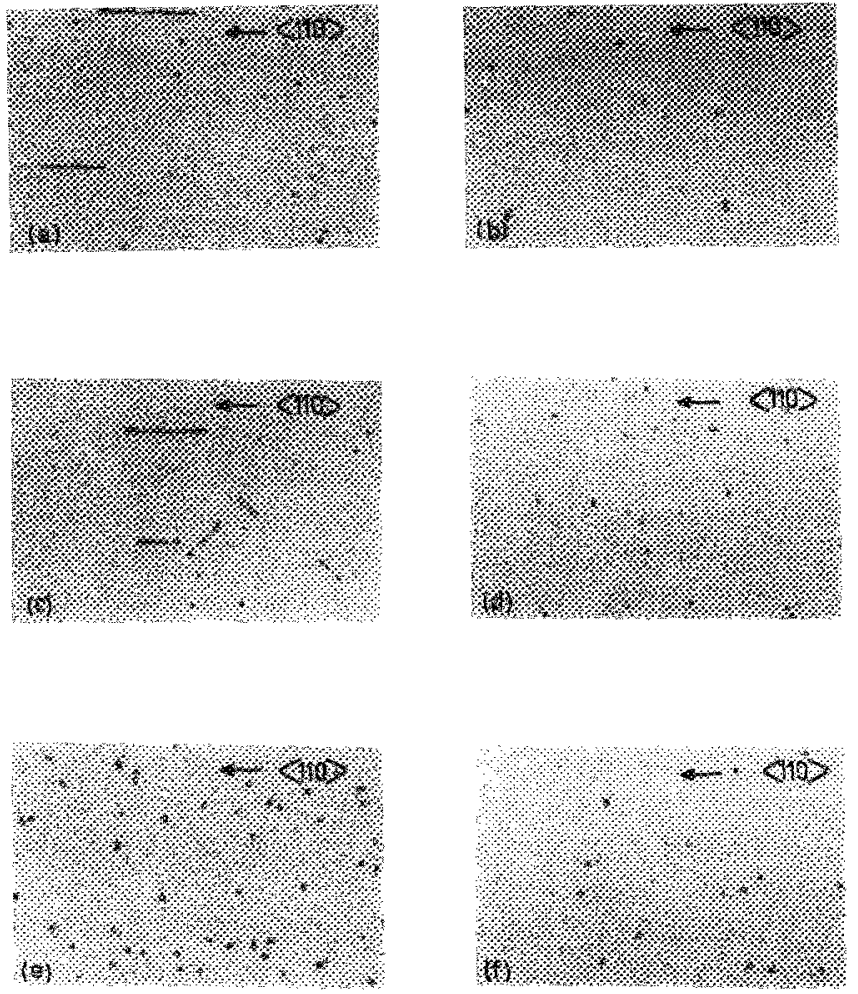

FIG. 2. Photomicrographs showing the defect etch patterns of the samples submitted to RTA. (a) Sample annealed at $1000^{\circ} \mathrm{C}$ for $1 \mathrm{~s}$, (b) sample annealed at $1000{ }^{\circ} \mathrm{C}$ for $25 \mathrm{~s}$, (c) sample anmealed at $1100^{\circ} \mathrm{C}$ for $1 \mathrm{~s}$, (d) sample annealed at $1100^{\circ} \mathrm{C}$ for $25 \mathrm{~s}^{3}$, (d) sample annealed at $1200^{\circ} \mathrm{C}$ for $1 \mathrm{~s}$, and (f) sample annealed at $1200^{\circ} \mathrm{C}$ for $25 \mathrm{~s}$. Secco etch $30 \mathrm{~s}$, magnification $800 \times$

was reduced by about two orders of magnitude. We also observe the generation of OSFBI with density comparable to that of the DL-etch pits. Prolonging the anneal at $1000^{\circ} \mathrm{C}$ for $25 \mathrm{~s}$ resulted in the complete suppression of the nuclei for OSF generation. With respect to the control sample, there is also a reduction of about four orders of magnitude on the density of DL-etch pits. Finally, one cannot observe any noticeable infuence of the anneal on the OSFBI density [see Fig. 2(b) ]. The oxidation of samples annealed at $1100^{\circ} \mathrm{C}$ for $1 \mathrm{~s}$ gives origin to a density of $6 \times 10^{4} \mathrm{~cm}^{-2}$ of extended Iinear defects. Their dimensions range from a few $\mu \mathrm{m}$ to $35 \mu \mathrm{m}$. Also, a small density of DLetch pits can be observed [see Fig. 2(c)]. These linear defects have a density of $6 \times 10^{4} \mathrm{~cm}^{-2}$ and are aligned with the $\langle 110\rangle$ or $\langle 100\rangle$ directions. We expected them to be the result of the transformation of OSF into a linear array of DL during the oxidation by an unfaulting reaction, as already reported by Shiraki. "Annealing performed at $1100^{\circ} \mathrm{C}$ for 25 s or at $1200^{\circ} \mathrm{C}$ for 1 or 25 $s$ resulted in complete elimination of nuclei for OSF generation, but did not avoid the generation of a low density of DL $\left(10^{3} \mathrm{~cm}^{-2}\right)$ and of a considerable density of OSFBI (3$5 \times 10^{5} \mathrm{~cm}^{-2}$ ) [see Figs. 2(d)-2(f)].

\section{DISCUSSIONS AND CONCLUSIONS}

The FA performed at low temperature $\left(480^{\circ} \mathrm{C}\right)$ or medium temperature $\left(800^{\circ} \mathrm{C}\right.$ ) for $1-10 \mathrm{~h}$, has shown weak effciency with respect to the suppression of the generation of extended defects during the subsequent steam oxidation. However, a significant reduction of the densities of OSF and DL-etch pit was attained after the high-temperature treatments performed at 1100 and $1200^{\circ} \mathrm{C}$ during 1 to $5 \mathrm{~h}$. On these high-temperature treated samples we detected another defect structure of elliptical shape having the maximum length of about $5 \mu \mathrm{m}$ and being aligned to the $\langle 110\rangle$ directions. This structure is similar to the one already observed by Rozgonyi et al. ${ }^{10}$ (labeled as OSFBI), which they identified as being small bulk stacking faults generated by the oxidation of the implanted silicon surface. In particular, for the annealing processes performed at $1200^{\circ} \mathrm{C}$, the density of generated OSFBI decreases with increasing annealing time, reaching an undetectable level after $5 \mathrm{~h}$. Concomitantly, an opposite behavior for the OSF density was observed. The annealing performed for $1 \mathrm{~h}$ resulted in a complete suppresssion of OSF generation, while on the samples submitted to more prolonged amnealing cycles ( 3 and $5 \mathrm{~h}$ ) OSF was again generated. In the last case, their densities increased with annealing time. This annealing behavior of OSF and OSFBI at $1200^{\circ} \mathrm{C}$ cycles, suggests that during these annealing processes the nuclei for OSFBI generation were continuously transformed into OSF nuclei while a small fraction of them was being annealed.

Compared to FA, all the RTA cycles were quite more efficient. We have to consider that in spite of the large densities of extended defects, the control sample has aiso been submitted to an anneal period of $5 \mathrm{~min}$ at high temperature $\left(1150^{\circ} \mathrm{C}\right)$ in $\mathrm{N}_{2}$ atmosphere before being oxidized. This time is longer than any experimented RTA cycles. Furthermore, the RTA performed at $1000^{\circ} \mathrm{C}$ for $1 \mathrm{~s}$ seems to be as effective as the FA performed at $1100^{\circ} \mathrm{C}$ for $5 \mathrm{~h} \mathrm{[compare}$ Fig, 2(a) with $[(e)$ and Table I with Table II ]. The samples annealed at $1200^{\circ} \mathrm{C}$ for 1 or $25 \mathrm{~s}$ exhibit densities and structures of defects comparable to those observed on the sample annealed at $1200^{\circ} \mathrm{C}$ for $1 \mathrm{~h}$ [compare Figs. $2(\mathrm{e})$ and 2 (f) with $1(\mathrm{~g})]$.

We attribute the significantly higher efficiency of the RTA process in the annealing of ion implantation damage, as compared to the FA, to the differences in the heating rate of the samples. The heating rate promoted by the RTA furnace is in the range of $200-300^{\circ} \mathrm{C} / \mathrm{s}$ while in the resistive furnace it is $\sim 4^{\circ} \mathrm{C} / \mathrm{s}$. A competition between the annealing of ion implantation damage and clustering of point defects occurs during the heating of the samples. High heating rates should favor the dissolution of the ion implantation damage while low heating rates should favor the clustering of point defects. These clusters are probably constituted by point defect precipitates, small dislocation loops, and stacking faults, which could not be suppressed during the anneaiing process. They play the role of nuclei for extended defect generation during the subsequent oxidation. Our results are in agreement with those published by Huang and Jaccodine. ${ }^{12}$ These authors observed a similar annealing enhancement of $\mathrm{B}^{+}$ implantation defects in silicon induced by tungsten-halogen lamp annealing, in the temperature range of $500-700^{\circ} \mathrm{C}$. They concluded that this enhancement of defect annealing was a consequence of the fast heating and the fast cooling of the samples promoted by the RTA process. 
In summary, we studied the amnealing of silicon substrates implanted with boron ions to a medium dose by means of conventional and rapid thermal annealing processes. We observed that the RTA presents higher efficiency than the FA does for the elimination of the implantation damage that acts as a nucleation center for the generation of extended defects during subsequent thermal oxidation of the implanted silicon. We suggested a model which takes into account the heating rate of the samples in order to explain the different annealing behaviors observed for the FA and the RTA processes.

\section{ACKNOWLEDGMENTS}

This work was partially supported by Finep, CNPq, and Sid Microeletrônica S.A.
'See, e.g., Rapid Thermal Processing, edited by T. O. Sedgwick, T. E. Seidel, and B. Y. Tasaur (MRS Symposia Proceedings, Pitisburgh, PA, 1986) Vol. 52 .

${ }^{2} S$. Namba, Nuclear Instrum. Methods 189, 175 (1981).

${ }^{3}$ R. W. Bicknell, in Proceedings of European Conference on Ion Impiantation, Readings, Englund (Peter Peregrinus, England, 1970), p. 57.

${ }^{4}$ M. Tamura, Appl. Phys. Lett. 23, 651 (1973).

${ }^{5}$ S. Prussin, J. Electrochem. Soc. 122, 830 (1975).

5. Prussin, J. Appl. Phys. 25,1635 (1974).

7Y. Hokari and H. Shiraki, Jpn. J. Appl. Phys. 26, 1899 (1977).

${ }^{8}$ Y. Hokari, Jpn. J. Appl. Phys. 18,873 (1979).

${ }^{3}$ G. A. Rozgonyi and T. E. Seidel, in Semiconductor Silicon 1977, edited by H. R. Huff and E. Sirtl (Electrochemical Society, New Jersey, 1977), p. 616.

10 F. Secco d'Aragona, J. Electrochem. Soc. 119, 948 (1972).

"H. Shiraki, in Semiconductor Silicon 1977, edited by H. R. Huff and E. Sirt (Electrochemical Society, New Yersey, 1977), p. 546.

${ }^{12}$ I. Huang and IR. I. Jaccodine, in Rapid Thermat Processing, edited by $\mathrm{T}$. O. Sedgwick, T. E. Seidel, and B. Y. Tsaur (MRS Symposia Proceedings, Pittshurgh, PA, 1986), Vol. 52, p. 57. 